\title{
DA EDUCAÇÃO RURAL À EDUCAÇÃO DO CAMPO: REVISÃO CRÍTICA
}

\author{
Mary Rangel * \\ Rosângela Branca do Carmo **
}

\section{RESUMO}

O propósito deste estudo é recuperar alguns dos eventos históricos da educação rural que esclarecem o percurso da evolução de seu significado para a concepção, social e politicamente mais ampla, da educação do campo, observando e problematizando, nesse percurso, fatores que fundamentam reivindicações por maior atenção à escola e às práticas pedagógicas. A metodologia inclui revisão de estudos, cujos aportes críticos sustentam a problematização, construída no estilo ensaístico. A revisão aponta um longo tempo de pouca atenção política ao contexto rural e suas escolas, cujo currículo e práticas têm sido submetidos ao modelo da escola urbana. Destaca-se, então, a relevância histórica de movimentos sociopolíticos em prol da valorização dos sujeitos do meio rural, incluindo indígenas e remanescentes dos quilombos, reconhecendo-se sua importância para a vida e a história do país. Assim, no percurso histórico e nos aportes críticos revistos neste artigo, observa-se a crescente ênfase em recursos e condições que propiciem a oferta de um processo educativo contextualizado, assegurando-se também os princípios de qualidade educacional. Desse modo, este estudo demonstra o quanto o campo inspira reflexões e requer a continuidade e aprofundamento de estudos que visibilizem suas questões e apelos.

Palavras-chave: Educação Rural. Revisão Crítica. Problematização. Educação do Campo.

\section{ABSTRACT \\ FROM RURAL EDUCATION, TO COUNTRYSIDE EDUCATION: A CRITICAL REVIEW \\ The purpose of this study is to recover some of the historic events of the rural education that clarify the route of the evolution of its significance to the conception, social and politically wider, from the field education, observing and questioning, in this route, factors that base claims for greater attention to school and its pedagogical}

\footnotetext{
* Doutorado em educação pela Universidade Federal do Rio de Janeiro (UFRJ). Pós-Doutorado em Psicologia Social pela Pontíifícia Universidade Católica de São Paulo (PUC/SP). Professora Titular de Didática da Universidade Federal Fluminense(UFF) Professora Titular da área de Ensino-Aprendizagem da Universidade do Estado do Rio de Janeiro (UERJ). Assessora Pedagógica: Institutos Superiores La Salle (RJ) e Colégio La Salle Abel (RJ). Endereço para contato: Universidade Federal Fluminense, Faculdade de Educação, Programa de Pós-Graduação em Educação, Campus do Gragoatá, CEP: 24.210-201 Niterói, RJ. mrangel@lasalle.org.br.

*** Mestrado em Educação pela Universidade Federal Fluminense (UFF). Professora do Departamento de Ciências da Educação da Universidade Federal de São João del-Rei (UFSJ). Endereço para contato: Universidade Federal de São João del-Rei. Praça Frei Orlando, 170, Centro, CEP: 36.307-352 São João del-Rei - Minas Gerais. branca@ufsj.edu.br
} 
practices. The methodology has included review of studies, whose critical contribution have sustained the questioning, constructed in the essay style. The review points to a long time of few political attention to the rural context and their schools, whose curriculum and practices have been submitted to the model of urban schools. It has been highlighted, though, the historic relevance of social political movements in favor of the valorization of the subjects from the rural environment, including indigenous and remaining of the quilombos, recognizing their importance to the life and history of the country. Thus, in the historical route and in the critical contributions reviewed in this article we have observed the growing emphasis in resources and conditions that favors the offer of a contextualized educational process, assuring also the principles of educational quality. This way, this study has demonstrated how the field inspires reflections and requires the continuity and deepening of studies that visualizes its questions and appeals.

Keywords: Rural Education. Critic Review. Questioning. Field Education.

\section{Introdução}

Na condução metodológica deste artigo, optouse por uma revisão de estudos sem a pretensão de esgotá-los, mas de reunir aportes significativos à problematização a que se propõe, e cujo estilo ensaístico é recorrente a Burke (1987) e Pinto (1998).

Inicia-se, então, observando que, historicamente, os primeiros indícios de visibilidade da educação no meio rural remontam ao século XIX. No entanto, apenas nos anos 30 do século XX começaram a surgir modelos de educação rural, baseados em projetos de modernização do campo, patrocinados por organismos de cooperação norte-americana e difundidos por meio do sistema de assistência técnica e extensão rural (CALAZANS, 1993). A proposta de modernização do campo foi orientada pelo modo de vida urbano, observando pouco as peculiaridades, saberes e valores do meio rural.

Esse problema tem motivado pesquisas, como a de Cavalcante (2003), em cujos dados e análises evidencia-se, nas políticas públicas para a escolarização das populações rurais, um fraco desempenho e o pouco interesse do Estado. $\mathrm{O}$ analfabetismo no Brasil, que permanece mais acentuado na área rural do que na área urbana, é uma das evidências.

Desse modo, assinala-se na trajetória da escola rural no Brasil o processo de expropriação/ proletarização das famílias agricultoras. Esse processo teve a contribuição do fato da escola ter sido incluída no processo de "modernização do campo", com base em uma concepção frágil e descontextualizada de "modernização", que também tem afetado a escola urbana e, historicamente, a educação brasileira. A crítica a esse problema tem sido recorrente na literatura, podendo-se exemplificar a discussão de Freire (2006) sobre autonomia e saberes relevantes às práticas pedagógicas, e as análises de Saviani (1983) sobre as teorias da educação e o problema da marginalidade. Observase, então, que quaisquer formas, circunstâncias ou contingências que provoquem mimetismo cultural fragilizam a escola, seja urbana, seja rural.

A reação a fatores que fragilizaram a escola rural encontra apoio político em movimentos sociais, como o Movimento dos Trabalhadores Sem Terra (MST), no qual se realça o empenho na concepção de que a importância da terra, como espaço e projeto de vida e trabalho, associa-se à importância da escola e do saber do campo (RAPOZO, 1999; LIMA, 1998; QUEIROZ, 1992). Por isso, as questões políticas da terra passam, necessariamente, pela educação do e no campo, cuja revisão de aportes críticos de sua história constitui motivo e proposta deste estudo e sua problematização.

\section{A educação e a escola do meio rural}

A educação no meio rural tem se apresentado como um dilema para famílias de agricultores que, frequentemente, se veem impelidos a trocar suas terras e sua vida no campo por subempregos 
nas periferias das cidades, movidos, entre outros fatores, pela ilusão de encontrarem uma escola que propicie a seus filhos oportunidades de emprego assalariado de bom nível. Ribeiro $(1985$, p.3) analisa essa situação, ressaltando que:

[...] mesmo para as famílias que enviam seus filhos para a escola rural, o ensino feito através desta escola não os prepara para permanecerem na terra. Toda a política para a educação rural tem se restringido a oferecer um arremedo da escola urbana, que nem habilita os filhos dos agricultores para dar continuidade às lides dos pais, nem os qualifica para os empregos urbanos.

Autores, como Richardson (1983) e Rocha (1998), baseados em relatos obtidos ao longo de 15 anos de pesquisas, ressaltam a precariedade estrutural e pedagógica da maioria das escolas rurais do Brasil. Cavalcante (2003) complementa a análise, assinalando que os problemas estruturais apresentam outros agravantes em aspectos pedagógicos, como cartilhas e livros didáticos totalmente descontextualizados do meio rural, com atividades que não correspondem à vivência do aluno. "As cartilhas eram escritas para as escolas urbanas, sem considerar o saber do camponês, e mantinham atividades inadequadas ao meio rural, como reconheciam algumas professoras, pois não havia muita preocupação em adaptá-las àquilo que seria de maior interesse" (CAVALCANTE, 2003, p. 25).

Outra constatação relacionada às escolas rurais do Brasil é a de que a maioria dessas escolas ainda funciona com classes multisseriadas. No que pese o papel histórico que desempenharam e continuam a desempenhar no interior do Brasil, as classes multisseriadas oferecem a professores e alunos condições precárias de estudo. Tal precariedade agrava-se ainda mais se relacionada à formação do professor. Assim, Cavalcante (2003) analisa a fragilidade da formação e o acúmulo de funções do professor na escola rural, assumindo vários níveis escolares numa mesma turma, além de outras funções, a exemplo da função de merendeiro.

Observa-se, então, que a educação rural, em seus aspectos pedagógicos, disciplinares e didáticos, tem sido concebida com base na ideia de que todos os alunos são iguais, independente das especificidades do meio em que vivem. Sendo assim, fica evidente que tanto o calendário quanto o currículo da maioria das escolas têm sido orientados pelas necessidades urbanas, impondo aos alunos do meio rural uma cultura desvinculada de seu contexto.

Contudo, vale ressaltar que a descontextualização de saberes e práticas pedagógicas, que tem afetado a escola rural, também ocorre na escola urbana. Entre os problemas e dilemas comuns encontram-se os que se referem a currículo, a metodologias de ensino, a livros didáticos, à desmotivação de alunos, e à formação de professores, que necessitam atuar com uma heterogeneidade de alunos e com as várias manifestações da diversidade social e do multiculturalismo. Problemas como a precariedade de recursos e de instalações físicas, bem como complicações decorrentes da distância que dificulta o acesso às escolas, são comuns ao meio urbano e rural. Pesquisas como a de Souza (2006), que focaliza $A$ fábrica de professores e a padronização do conhecimento, trazem subsídios significativos ao estudo da descontextualização da escola, sem distinção de urbana ou rural. Contribuem, também, a essa análise os enfoques da literatura crítica sobre currículo, a exemplo de Silva (2001); sobre avaliação, a exemplo de Werneck (2000); e livro didático, a exemplo de Passini (2000), além de outros tantos estudos e temas das perspectivas amplas, profundas e complexas da problematização da escola.

Voltando a focalizar, mais especificamente, o meio rural, observa-se que as dificuldades de inadequação ao contexto, aliadas à precariedade de material, falta de incentivo dos pais, problemas relacionados ao acesso, locomoção, transporte escolar e deficiente formação do professor têm acarretado aos alunos um baixo rendimento e expressiva evasão escolar, com perspectivas de escolarização inferior ao $4^{\circ}$ ano do ensino fundamental. Além disso, como observa Werle $(2007$, p. 10), “[...] o tema da educação rural é pouco difundido como área de pesquisa e de formação, seja em cursos de graduação, seja na Pós-Graduação".

A necessidade de trabalho dos alunos na roça e a condescendência dos professores, que não registram suas faltas, constituem também fatores que prejudicam o seu aproveitamento escolar. Contudo, vale observar que as representações do 
trabalho para a mulher e o homem do campo não se limitam a aspectos profissionais e financeiros, mas assumem um particular significado na sua escala de valorização social, embora o trabalho nem sempre seja remunerado e absorva até mesmo atividades domésticas.

A questão do trabalho infantil é compreendida não como forma de exploração, mas de obrigação familiar, que deve ser cumprida. Desde muito pequenas, as crianças aprendem os ofícios próprios do campo e estão também envolvidas com os trabalhos domésticos, com os quais dividem seu tempo na escola. Essa dupla jornada de atividades, percebida como normal pelos pais, compromete a aprendizagem das crianças pelo cansaço, em razão do esforço dispendioso (CAVALCANTE, 2003).

É importante também, nessa sequência de análises, levar em conta as contribuições de estudos sobre o "trabalho como princípio educativo", considerando-se, em Saviani (2003, p. 13), que um de seus significados essenciais se expressa no "[...] ato de produzir, direta e intencionalmente, em cada indivíduo singular, a humanidade, produzida histórica e coletivamente pelo conjunto dos homens". Nesse sentido, o "trabalho como princípio educativo" é uma atividade mediadora entre o indivíduo e a cultura humana. Com essa mesma perspectiva, Arroyo (2008, p, 76) observa que “[...] a experiência que nos move a todos é a experiência do trabalho, da produção, o ato produtivo que nos produz como pessoas".

É interessante, ainda, a leitura de Frigotto (1985), quando propõe a superação de ambiguidades na discussão do "trabalho como princípio educativo", assim como a leitura da ampla discussão política que ele oferece em todos os seus trabalhos, com atenção especial à "produtividade da escola improdutiva", em que se encontra, com expressiva densidade teórica, a crítica à teoria do capital humano e sua influência em concepções da relação entre educação e trabalho pautadas na "[...] economia neoclássica e na ideologia positivista" (FRIGOTTO, 1990, p. 15-16).

É oportuno ainda observar que, a despeito de toda a dificuldade e precariedade das condições de ensino em escolas no meio rural, pode-se perceber que a educação é vista pela maioria dos pais como uma forma dos filhos "escaparem" das privações e dificuldades da vida no campo. Para Griffiths (1980, p. 44),

[...] a escola moderna não se originou em qualquer tentativa de comunidades rurais para melhorar sua própria maneira de vida. Foi introduzida por estrangeiros, corpos religiosos ou governos coloniais, e sua primeira consequência econômica foi atrair alguns jovens mais inteligentes para o serviço amanuense e outros empregos de escritório. Persiste essa tradição, sendo improvável que tal situação se modifique enquanto o trabalho agrícola não oferecer melhores resultados financeiros, estabilidade e conforto do que os empregos de escritório.

Skliar (2003), entre outros pesquisadores que trazem contribuições às análises numa perspectiva crítico-social, assinala que os sujeitos do campo têm sido tratados, predominantemente, ao longo da história, como indivíduos de menor valor, que adquirem representatividade quando são necessários à mão de obra rural, ou como instrumentos políticos em períodos eleitorais. Desse modo, o entendimento da construção da identidade desses sujeitos pressupõe a lógica da invisibilidade, ou seja, eles estão presentes nos lugares educativos, mas não possuem suas especificidades reconhecidas.

Assim, o homem do campo permanece ausente da história de sua própria cultura, pois tem sua linguagem, sua origem social, seus saberes desqualificados em nome de um modelo de valorização social hegemônico. "Na realidade, percebe-se a sutil hostilização da diversidade, porque existem mecanismos oficiais e toleráveis de exclusão, bastando analisar o processo de avaliação, o currículo, os decretos e as leis que adotam a perspectiva do sujeito homogêneo na educação". (SKLIAR, 2003, p. 19).

Embora a perspectiva homogeneizadora tenha dominado as diretrizes governamentais e, com base nelas, as políticas públicas no cenário educacional brasileiro, percebe-se um movimento contrário, sobretudo nas três ultimas décadas, a partir da abertura política, a fim de contextualizar não só a educação do campo, como a urbana, e realçar o valor social de seus sujeitos, compreendendo-os como agentes de sua construção histórica (CONAE, 2010).

Os sujeitos do meio rural, assim como os do meio urbano, interagem em suas comunidades, e o 
fazem de modo próprio, de acordo com suas experiências e expectativas sociais. Essa percepção requer de todos os envolvidos com as questões educacionais uma nova compreensão do contexto, interesses e motivações desses sujeitos, reconhecendo-se seu valor e possibilidades de realizações.

Essa compreensão mais ampla, mais contextualizada, tem contribuído à educação do campo, seus sujeitos, suas realizações, que passam a representar uma vertente de investigações de especial interesse na educação brasileira, na perspectiva de tornar mais visível o locus rural de conhecimento e cultura, considerando e valorizando suas especificidades e suas práticas (ARROYO, 2008; RIBEIRO, 1985; MENEZES, 2010; ARAUJO, 2010; CULTI; SOUZA, 2010).

Baseando-se nas considerações anteriores, pode-se verificar que a história da educação escolar no meio rural no Brasil tem sido marcada por duas formas de organização bem distintas, que refletem, de maneira significativa, a percepção social da identidade dos sujeitos do campo. A primeira perspectiva histórica, mais facilmente identificada, e que tem se mantido ao longo do tempo, é a da implantação do ensino rural de acordo com o modelo de escola dos centros urbanos. A segunda perspectiva, de abordagem mais recente, pauta-se na adoção de práticas e propostas pedagógicas específicas do universo rural, com suas características, interesses e contribuições sociais, políticas econômicas e culturais, sem esquecer a presença, nesse universo, de grupos indígenas e de remanescentes dos quilombos. Essa forma contextualizada de percepção tem, no saber de homens e mulheres do campo, um dos seus pilares de sustentação.

Entretanto, o resgate da identidade e da importância histórica e sociopolítica dos sujeitos do campo, com a colaboração do processo educativo, permanece, ainda, como um ideal que motiva educadores preocupados com a atenção e respeito a essa identidade e sua pouca valorização por várias gerações.

Vive-se, portanto, um tempo em que outros caminhos vêm sendo traçados para a educação do meio rural no Brasil, como apontam Souza (2006), Caldart (1996; 1997), Arroyo (2008). O momento, como assinala Arroyo (2008), é de avanços, de modo que a educação do campo passa a receber maior consideração; esse momento, portanto, é especialmente instigante a estudos que reveem o seu percurso histórico e, nele, eventos significativos, substanciais à sua problematização, no interesse de realçar a importância de vencer os desafios que o passado deixou ao presente e fortalecer a confiança na construção de um novo tempo e uma nova história.

Desse modo, nas propostas atuais para a educação escolar no meio rural, inclui-se a ampliação do seu entendimento e seu alcance, que se expressam nos significados da educação do campo, com atenção a todos os seus espaços e sujeitos, reconhecendo e qualificando suas inquietações e seus questionamentos ao tipo de educação que lhes tem sido oferecida e às dificuldades de exercício pleno de seus direitos, como trabalhadores e cidadãos. Por isso, a educação do campo constitui-se, também, num " [...] espaço propício para reflexões sobre interdisciplinaridade, uma vez que o próprio campo caracteriza-se por uma diversidade cultural, social e econômica" (SOUZA, 2006, p. 24). Nessa mesma perspectiva de valorização, vale lembrar que a história da escola rural expressa, de modo significativo, a história da organização da sociedade brasileira, e que, desde o período da colonização até o início do século XX, a população do Brasil era predominantemente rural.

Assim, a renovação de significados que se expressam na educação do campo associa-se à própria reconstrução de sua história e de circunstâncias de subalternidade, como as do período colonial, em que o modelo formal de escola era destinado aos filhos das elites agrárias que se formavam nos colégios jesuítas, nos quais recebiam os conteúdos clássicos (gramática, humanidades, retórica, filosofia, teologia), propícios a que desempenhassem, no futuro, cargos públicos, ou seguissem o sacerdócio ou a advocacia.

Nesta revisão histórica, vale também lembrar que, somente no texto da Lei de 15 de outubro de 1827, em seu artigo primeiro, pode-se notar um aceno para o contexto do campo, nos seguintes termos que determinam: "[...] em todas as cidades, vilas e lugarejos mais populosos haverá escolas das primeiras letras que forem necessárias". Essa lei foi a primeira e única sancionada em todo o período colonial (FARIA FILHO, 2000). Obviamente, ela 
fracassou, pois não havia estrutura econômica, social, política e técnica que desse sustentação às vinte escolas criadas em todo o território nacional, e quanto mais longínqua a localidade, mais raramente chegavam os recursos necessários ao seu funcionamento.

A maior clareza da importância da educação no meio rural foi suscitada pelo intenso deslocamento da população do campo para os centros urbanos, ocorrido a partir dos anos 1910/1920, em virtude do incremento do processo de industrialização. Como exemplos desse incremento, podem-se citar a instalação de importantes polos industriais em São Paulo, bem como a implantação de fábricas têxteis e da companhia Belgo-Mineira em Minas Gerais, para a exploração siderúrgica (LEITE, 2002). Especialmente esses estados atraíam a população rurícola, o que levou ao surgimento do "Ruralismo Pedagógico", cujo propósito era, a priori, adaptar a escola às condições do homem do campo e, consequentemente, mantê-lo em sua região de origem.

$\mathrm{Na}$ realidade, a defesa da proposta do "Ruralismo Pedagógico", feita pelos agroexportadores, com apoio de setores da elite urbana, do movimento nacionalista e do movimento católico do início do século, justifica-se pelo interesse na permanência do homem no campo, na manutenção da riqueza agrícola e na tentativa de conter a explosão dos problemas sociais nas cidades. Várias medidas foram tomadas nesse período com o objetivo de implementar a política nacionalista do Ministério da Educação por meio de projetos, como:

\section{[...] a) a criação do Fundo Nacional do Ensino Primá- rio (FNPE), cujos recursos seriam dedicados apenas à construção de prédios escolares; b) a fundação do Instituto Nacional de Estudos Pedagógicos (INEP), peça-chave das políticas educacionais oriundas do Ministério da Educação; c) a implantação da Radio- difusão Rural; d) a criação do Conselho Nacional de Educação Primária (CNEP); e, finalmente, e) a realização da governista Conferência Nacional de Educação [...] com vistas a comprovar [...] as precárias condições do ensino elementar agrícola (MENDONÇA, 2007, p. 47).}

Não obstante, em 1930, o processo migratório ter se tornado significativo, dois terços da população continuava no campo, embora permanecesse desprovido das atenções e recursos necessários ao ensino escolar (CALAZANS; CASTRO; SILVA, 1985). Esse cenário manteve-se até a década de 1930 , pois, conforme Leite (2002, p. 60), "prevaleceram, até então, a sociedade e o Estado oligárquico, com todas as suas características e formas tradicionais de exercício de poder, não promovendo rupturas significativas entre os setores agrário e industrial".

No governo de Getúlio Vargas, a escola rural permaneceu com pouca atenção, ressalvando-se apenas a criação, em 1937, da Sociedade Brasileira de Educação Rural, cujo propósito era o de incentivar a permanência no campo, preservar a arte e manifestações folclóricas rurais, bem como proporcionar a expansão do ensino. A disciplina, o civismo e a obediência às normas do Estado eram princípios ideológicos que fundamentavam a Associação.

Algumas iniciativas pontuais para a educação rural foram tomadas a partir da década de 1940, movidas também pela proposta de "fixar o homem no campo". Contudo, o êxodo rural continuou crescendo. As iniciativas em prol do ensino rural nessa época encontraram emperramentos na implantação de programas e políticas, pois à difícil permanência do professor nas localidades das escolas somavase a ausência de condições de trabalho, de salários dignos, além de lacunas na formação profissional necessária à prática docente.

Os vários programas implementados nas décadas de 1930 e 1940 foram prejudicados por fatores que, ainda hoje, interferem nas possibilidades de contribuições efetivas à educação do campo, como o precário conhecimento do contexto de origem dos sujeitos, a pouca participação das escolas nas decisões que regulam o seu funcionamento e a inadequação das políticas às reais demandas do meio rural.

Em 1947, a Organização das Nações Unidas para a Educação, a Ciência e a Cultura (UNESCO) apresentou recomendações ao trabalho pedagógico no campo, priorizando o ensino de técnicas agrícolas no nível fundamental. Essas recomendações enfatizavam a importância de cuidados com as condições sanitárias e de oferta educacional, inclusive para a escolarização de adultos (WERLE, 2007, p. 11). 
As décadas de 1950 e 1960 caracterizaram-se pelo aumento, ainda maior que o dos períodos anteriores, do processo migratório do homem do campo em busca de melhores condições de vida. Conforme Souza (2006), nesse período, praticamente $50 \%$ da população brasileira vivia no campo e sua fixação não seria resolvida apenas por programas educacionais, mas sim por projetos políticos mais amplos, em favor de assegurar condições e direitos de qualidade de vida, em todos os seus aspectos de infraestrutura, saneamento, saúde e trabalho. Leite (2002, p. 37) acrescenta observações a essa análise, assinalando que "[...] os pequenos grupos rurais - trabalhadores sem terra, arrendatários, boias-frias e outros - não tinham vez e nem voz frente às decisões comunitárias", pois essas decisões eram de aplicação geral e não se destinavam a grupos específicos.

As circunstâncias de deterioração da educação rural, incluindo os efeitos da política de municipalização, que submeteu as escolas rurais aos precários recursos das prefeituras municipais, foram propícias a reações que se consubstanciaram em movimentos, como os dos Centros Populares de Cultura (CPC) e o Movimento Educacional de Base (MEB), "ligados a partidos de esquerda e com sustentação ideológica no trabalho desenvolvido pelas ligas camponesas, sindicatos e ação pastoral de bispos da igreja católica" (SOUZA, 2006, p. 54).

Outras ações educativas relevantes foram as dos Grupos de Alfabetização de Adultos e Educação Popular, movimento político-educacional que assumiu a luta contra a expropriação da terra de homens e mulheres do campo. Esse movimento culminou com a aprovação do Estatuto da Terra, em 1963. Embora o período fosse conturbado, por conta do regime militar implantado no Brasil em 1964, várias propostas de educação popular para o campo começaram a surgir, com especial atenção às ideias freireanas, notando-se então que, a despeito da perseguição a Paulo Freire, culminando com seu exílio em setembro de 1964, essas ideias superaram as pressões ideológicas e permaneceram com expressivo reconhecimento e contribuições à educação brasileira.

Observa-se, ainda, neste contexto dos anos 1960, a presença histórica do Movimento Brasileiro de Alfabetização (MOBRAL), criado pela Lei $n^{\circ}$
5.379, de dezembro de 1967, para ações movidas pela especial atenção à alfabetização de adultos, tanto em áreas urbanas quanto rurais. Embora trouxesse esperanças à população, faltou às ações do MOBRAL o atendimento necessário às peculiaridades de cada região brasileira, o que inibiu progressos sociais mais amplos.

É relevante lembrar que o Brasil presenciou nos anos de 1960 e 1970 a ascensão do regime militar e a abertura do país ao capital e a modelos estrangeiros de desenvolvimento, sobretudo os norte-americanos. No que se refere à educação, destaca-se a ação da Agência dos Estados Unidos para o Desenvolvimento Internacional (USAID), que visava contribuir com recursos no interesse da efetivação de ações no âmbito educacional. Nesse processo, os acordos MEC-USAID interferiram também na escola rural, entre outras formas pela importação do modelo de nucleação norte-americano, iniciado no Brasil em 1976. Entretanto, com o declínio do regime militar, consequentemente tal interferência sofreu interrupções, uma vez que a injeção de capital estrangeiro não apresentava o mesmo volume observado anteriormente, em decorrência, inclusive, da crise vivenciada pelo próprio modelo de produção capitalista. É interessante, então, observar a análise de Leite (2002, p.35): “[...] o sistema escolar controlado pela ideologia da caserna limitou-se aos ensinamentos mínimos necessários para a garantia do modelo capitalista-dependente e dos elementos básicos de segurança nacional".

Com o movimento crescente pela democratização na década de 1980, e apoiado no objetivo de erradicar o analfabetismo, que dava mostras de problema "incurável" na sociedade brasileira, foram implantados projetos, como o Programa Nacional de Ações Socioeducativas e Culturais para o Meio Rural (PRONASEC) e o Programa Educação Rural (EDURURAL).

Como observa Leite (2002), esse quadro da educação do campo permaneceu até o III Plano Setorial de Educação, Cultura e Desportos (PSECD), implementado para o período de 1980-1985, que propôs melhorias na condição de vida, de trabalho e de educação da população do campo, enfatizando a expansão do ensino fundamental e a redução da evasão e repetência escolar. Entretanto, algumas 
medidas cruciais para a implantação e fortalecimento de condições da educação do campo previstas nesse plano foram desconsideradas, como a formação dos professores para atuação no meio rural, a adequação do material didático e as necessárias melhorias das instalações físicas das escolas.

Já ao final do regime militar, nos anos de 1980 a 1985, implantou-se, no nordeste, o EDURURAL, uma parceria entre o governo federal e a Universidade Federal do Ceará, com financiamento do Banco Internacional para Reconstrução e Desenvolvimento (BIRD). Esse programa pretendia avanços nos conceitos e práticas da educação, considerando as críticas a "[...] currículos urbanos introduzidos na zona rural" e destacando a proposta de "[...] autonomia pedagógica, de modo a valorizar o trabalho de professores e alunos, enfatizando a realidade campesina" (LEITE, 2002, p. 50).

Iniciativas como o EDURURAL fundamentaram-se em princípios educativos de movimentos populares e receberam influências de teorias da aprendizagem com enfoque sociocultural. Observase, então, que o conceito de educação rural torna-se insuficiente para comportar a complexidade da educação destinada ao homem do campo. Nesse sentido, é importante, também, reconhecer as contribuições do Encontro Nacional de Educadoras e Educadores da Reforma Agrária, em 1998, realizado em Luziânia, Estado de Goiás.

Finalmente, assinala-se que a educação do campo incorpora, em sua concepção, seus fundamentos e seu significado, um projeto político-pedagógico de alcance amplo, que inclui, em suas motivações, as do MST, e encontra, hoje, crescente atenção nas discussões acadêmicas, movidas pelo interesse na promoção e reconhecimento do expressivo valor de homens e mulheres do campo, com especial atenção à garantia de seus direitos, como: valorização de seu trabalho; condições de vida cidadã; e educação que atenda aos seus interesses, mantendo-se o mesmo princípio de qualidade social e pedagógica proposta à educação do meio urbano.

Ressalvadas as limitações do alcance de análises e aportes deste estudo, acredita-se que seja possível distinguir a proposta do "ruralismo pedagógico" da proposta de ressignificação da educação do campo, mais ampla por conta do reconhecimen- to das tradições, dos costumes, do valor do trabalho da população do campo, compreendendo-se, ainda, que a permanência dos sujeitos no meio rural possa ser ressignificada mediante sua valorização sociopolítica e a valorização do significado que atribuem à terra, como fonte de conhecimento, produção, vida e convivência.

Acredita-se, ainda, que a expressão "educação do campo" possa ter um sentido mais abrangente e inclusivo (também ressignificado em relação à educação rural), contribuindo à maior visibilidade de grupos, como quilombolas e indígenas, e à sua maior consideração social e política.

Contudo, não se desconsidera, ao contrário, enfatiza-se, a necessidade de estudos e pesquisas que aprofundem essas questões, que vão além de nomenclaturas e materializam-se na complexidade da relação entre propostas e práticas efetivas.

\section{Comentário conclusivo}

Espera-se que a perspectiva de ampliar o significado da expressão "educação rural" para o de "educação do campo" possa significar mais do que, simplesmente, uma alteração semântica e contribuir com o desenvolvimento de políticas efetivas em favor de um número significativo de trabalhadores e trabalhadoras que têm sido excluídos do processo de escolarização durante a história socioeducacional brasileira. Essa exclusão constitui, atualmente, um especial foco de atenção dos educadores e sua ênfase na "[...] valorização da educação do campo, quilombola e escolar indígena, a partir de uma visão que as articule ao desenvolvimento sustentável" (CONAE 2010, p. 37). Propõe-se, nesse mesmo sentido de resgate histórico:

Criar e manter as escolas do campo de acordo com os padrões básicos de infraestrutura que contemplem: transporte escolar intracampo, equipamentos tecnológicos de informação e comunicação agrícolas, material didático, acervo bibliográfico, quadra esportiva, laboratórios científicos e de informática com acesso à internet com qualidade, a qualificação e formação continuada para o uso das tecnologias pelos/as educadores/as, custeadas pelo poder público, salas de aula adequadas e equipadas. (CONAE 2010, p. 136).

Chega-se, portanto, ao ano 2011, com reivindicações expressivas de atenção política à educação 
do campo, incluindo a de que as previsões que constam do documento final da Conferência Nacional de Educação (CONAE 2010), assim como as perspectivas do Plano Nacional de Educação (PNE), em discussão para a década 2011-2020, traduzam-se em ações efetivas para consolidar avanços de princípios, concepções e propostas, e de exercício de direitos de homens e mulheres do campo, com real inclusão dos indígenas e dos remanescentes dos quilombos.

Reivindica-se, sobretudo, que sejam asseguradas condições de qualidade social, política e pedagógica da educação, da escola, do ensino básico - fundamental e médio - no interesse e dever de resgatar os valores e direitos do campo, reconstruindo e superando uma história marcada por descasos, desconsideração e subalternidade.

\section{REFERÊNCIAS}

ARAUJO, S. R. M. de. Educadores do campo: descobrindo os caminhos da formação inicial para os monitores das Escolas Famílias Agrícolas do Estado da Bahia. Revista da Faeeba. Educação e Contemporaneidade. Salvador, v. 19, n. 34, p. 131-144, 2010.

ARROYO, M. A educação básica e o movimento social do campo. In:

C. (Orgs.). Por uma educação do campo. Petrópolis: Vozes, 2008. p. 147-158. ; CALDART, R. S.; MOLINA, M.

BURKE, P. The historical anthropology of early modern Italy: essays on perception and communication. Cambridge [Cambridgeshire]; New York: Cambridge University Press, 1987.

CALAZANS, M. J. Para compreender a educação do Estado no meio rural - traços de uma trajetória. In: THERRIEN, J.; DAMASCENO, M. N. (Coords.). Educação e escola no campo. Campinas: Papirus, 1993. p. 172-184.

; CASTRO, L. F. M. de; SILVA, H. R. S. Questões e contradições da educação rural no Brasil. In: WER$\overline{\text { THEIN }}$, J.; BORDENAVE, J. Díaz (Orgs.). Educação rural no Terceiro Mundo: experiências e novas alternativas. Rio de Janeiro: Paz e Terra, 1985. p. 179-188.

CALDART, R. S. Os movimentos sociais e a construção da escola (do sonho) possível. Contexto \& Educação. Ijuí, s.n., v. 10, n. 41, p. 100-131, jan./mar. 1996.

. Educação em movimento - Formação de educadores e educadoras no MST. Petrópolis: Vozes, 1997.

Por uma educação do campo: traços de uma identidade em construção. In: ARROYO, M. C.; CALDART, R. S.; MOLINA, M. C. Por uma educação do campo. Petrópolis: Vozes, 2008. p. 147- 58.

CAVALCANTE, R. L. A. A escola rural e seu professor no "Campo das Vertentes". 2003. Tese (Curso de Doutorado em Educação) - Faculdade de Educação, Pontifícia Universidade Católica, Rio de Janeiro, 2003.

CONAE 2010. Conferência Nacional de Educação. Construindo o Sistema Nacional Articulado de Educação: o Plano Nacional de Educação, Diretrizes e Estratégias de Ação. Documento Final. Brasília: Imprensa Oficial, 2010.

CULTI, M. N.; SOUZA, J. B. da L. Estratégia de comercialização para melhorar a renda de pequenos produtores familiares rurais de leite. Revista da Faeeba. Educação e Contemporaneidade. Salvador, v. 19, n. 34, p. 175-189, 2010.

FARIA FILHO, L. M. de. Instrução elementar no século XIX. In: LOPES, E. M. T. (Org.). 500 anos de educação no Brasil. Belo Horizonte: Autêntica, 2000. p. 45-86.

FREIRE, P. A pedagogia do oprimido. Rio de Janeiro: Paz e Terra, 1987.

. Pedagogia da autonomia: saberes necessários à prática educativa. São Paulo: Paz e Terra, 2006.

FRIGOTTO, G. A produtividade da escola improdutiva: um (re) exame das relações entre educação e estrutura econômico-social capitalista. São Paulo: Cortez; Autores Associados, 1990.

Trabalho como princípio educativo: por uma superação das ambiguidades. Boletim técnico do SENAC. Rio de Janeiro, v. 11, n.3, p. 175-192, set./dez. 1985.

GRIFFTHS, V. L. Problemas da educação rural. Cadernos de Pesquisa. São Paulo, n. 10, p. 41-55, 1980. 
LEITE, S. C. Escola rural: urbanização e políticas educacionais. São Paulo: Cortez, 2002.

LIMA, M. B. de. Do saber da conquista à conquista do saber: educação e autonomia no campo. 1998. Dissertação (Mestrado em Educação) - Faculdade de Educação, Universidade Federal do Ceará. Fortaleza, 1998.

MENDONÇA, S. R. Estado e educação rural no Brasil: alguns escritos. Niterói, RJ: Vício de Leitura; FAPERJ, 2007.

MENEZES, I. D. A cor do invisível: saberes nas experiências educativas organizadas pela central das associações das comunidades de fundo e fecho do pasto da região do Senhor do Bonfim. Bahia. Revista da Faeeba. Educação e Contemporaneidade. Salvador, v. 19, n. 34, p. 97-108, 2010.

PASSINI, E. Y. Alfabetização cartográfica e o livro didático: uma análise crítica. Belo Horizonte: Lê, 2000.

PINTO, M. da C. Um elogio do ensaio. São Paulo: Ateliê Editorial, 1998.

QUEIROZ, Z. F. de. A escola rural e a questão do saber: do saber universal ao saber construído pelo homem do campo. Dissertação. 1992 - Faculdade de Educação, Universidade Federal do Ceará, Fortaleza, 1992.

RAPOSO, M. da C. A dimensão pedagógica dos movimentos sociais no campo. São Luis, MA: Edufma, 1999.

RIBEIRO, C. de J. História de uma escola para o povo: projeto João-de-Barro-Maranhão. São Luís: UFMA, 1985.

RICHARDSON, R. J. Pobreza rural, desenvolvimento e educação. Educação \& Sociedade, São Paulo: n. 14, p. 71-82, abr. 1983.

ROCHA, M. I. A. A construção histórica da escola no meio rural em Minas Gerais. Cadernos de Textos do $1^{\circ}$ Encontro Estadual de Minas Gerais, Belo Horizonte, p. 5-12, 1998.

SAVIANI, D. As teorias da educação e o problema da marginalidade. In: . Escola e democracia. São Paulo: Cortez, 1983. p. 7-49.

. Pedagogia histórico-crítica: primeiras aproximações. 8 ed. Campinas, SP: Autores Associados, 2003.

SILVA, T. T. O currículo como fetiche: a poética e a política do texto curricular. Belo Horizonte: Autêntica, 2001.

SOUZA, M. A. Educação do campo: propostas e práticas do MST. Petrópolis: Vozes, 2006.

SOUZA, M. F. do V. de. A fábrica de professores e a padronização do conhecimento. 2006. Tese (Doutorado em Educação) - Faculdade de Educação, Universidade Federal do Rio Grande do Norte, Natal, 2006.

SKLIAR, C. Pedagogia improvável da diferença. E se o outro não estivesse ai? Rio de Janeiro: DP\&A, 2003.

WERLE, F. O. C. Educação rural em perspectiva internacional. Ijuí: Ed. Unijuí, 2007.

WERNECK, H. Se a boa escola é a que reprova, o bom hospital é o que mata. 8 ed. Rio de Janeiro: DPA, 2000.

Recebido em 28.04.2011

Aprovado em 18.08.2011 